\title{
Response to a statement by Stein
}

\author{
Bernt Christian Skottun \\ Ullevaalsalleen $4 \mathrm{C}$ \\ 0852 Oslo \\ Norway \\ e-mail: berntchrskottun@gmail,com
}

Short heading: Response to Stein

\begin{abstract}
Stein (2019 Neuropsychologia 130, 66-77) writes: "Gross-glenn [sic] et al. (1995) found that dyslexic individuals had markedly reduced contrast sensitivity for gratings flickered at 10-60 Hz compared with good readers ...". To what this is supposed to refer is hard to understand given that Gross-Glenn et al. (1995, Visual Neuroscience, 12, 153-163) did not employ flickering stimuli.
\end{abstract}

Key words: Contrast, sensitivity, dyslexia, magnocellular, parvocellular. 
Stein (2019, p. 70) writes "Gross-glenn [sic] et al. (1995) found that dyslexic individuals had markedly reduced contrast sensitivity for gratings flickered at 10-60 Hz compared with good readers ...". This is puzzling since we (Gross-Glenn et al., 1995) did not make use of flickering stimuli. What we did do was to determine contrast sensitivity to stimuli of various durations. As we went to some length to make clear, because all such stimuli have their largest amplitudes at the very lowest temporal frequencies it is difficult, based on our data, to draw any conclusions about sensitivity to stimuli modulating at specific temporal frequencies. Stein discussed our study within the context of linking dyslexia to magnocellular deficits. Lest there be any misunderstanding it should be pointed out that we found the largest contrast sensitivity loss with stimuli at high spatial frequencies $(12 \mathrm{c} / \mathrm{deg})$. In the case of low frequency $(0.6 \mathrm{c} / \mathrm{deg})$ stimuli only small reductions were observed. (Both stimuli were tested with the same set of stimulus durations.) Our results are the direct opposite of what would have been expected for a magnocellular deficit and suggest, as we pointed out, a parvocellular (or sustained) system deficiency rather than a magnocellular one. Contrast sensitivity is presumably the best established psychophysical test of magnocellular integrity. However, tests of contrast sensitivity have provided little support for linking dyslexia to magnocellular deficits (Skottun, $2000,2015)$.

\section{REFERENCES}

Gross-Glenn, K., Skottun, B. C., Glenn, W., Kushch, A., Lingua, R., Dunbar, M., Jallad, B., Lubs, H. A., Levin, B., Rabin, M., Parke, L. A. \& Duara, R. (1995) Contrast sensitivity in dyslexia. Visual Neuroscience, 12, 153-163.

Skottun, B. C. (2000) The magnocellular deficit theory of dyslexia: the evidence from contrast sensitivity. Vision Research, 40, 111-127.

Skottun, B. C. (2015). The need to differentiate the magnocellular system from the dorsal stream in connection with dyslexia. Brain and Cognition. 95, 62-66.

Stein, J. (2019) The current status of the magnocellular theory of developmental dyslexia. Neuropsychologia, $130,66-77$. 